period of nutritional deprivation has been shown to have an objective effect on the small intestine.

\section{REFERENCES}

1. Rothman D, Latham MC, Walker WA 1982 Transport of macromolecules in malnourished animals. I. Evidence of increased uptake of intestinal antigens. Nutr Res 2:467-473

2. Worthington DB, Boatmann ES, Kenny GE 1974 Intestinal absorption of intact protein in normal and protein-deficient rats. Am J Clin Nutr 27:276286

3. Chandra RK 1975 Food antibodies in malnutrition. Arch Dis Child 50:532534

4. Udall JN, Pang K, Fritze L, Kleinman R, Walker WA 1981 Development of gastrointestinal mucosal barrier. I. The effect of age on intestinal permeability to macromolecules. Pediatr Res 15:241-244

5. Laurell CB 1966 Quantitative estimation of proteins by electrophoresis in agarose gel containing antibodies. Anal Biochem 15:45-52

6. Hummel $\mathrm{BC} 1959$ A modified spectrophotometric determination of chymotrypsin, trypsin and thrombin. Can J Biochem 37:1393-1399
7. Barbezat MS, Hausen JDL 1968 The exocrine pancreas and protein-calorie malnutrition. Pediatrics 42:77-92

8. Hatch T, Branski D, Krasner J, Lebenthal E 1978 The effect of acquired postnatal malnutrition on pancreatic enzymes in the rat. Pediatr Res 12:435

9. Wachstein M, Meisel E 1954 Relation of dietary protein levels to pancreatic damage in the rat. Proc Soc Exp Med 85:314-317

10. Udall JN, Bloch J, Vachino G, Feldman P, Walker WA 1984 Development of the gastrointestinal mucosal barrier. IV. The effect of inhibition of proteolysis on the uptake of macromolecules by the intestine. Biol Neonate 45:289-295

11. Telemo E, Westrom BR, Karlsson BW 1982 Proteolytic activity as a regulator of the transmission of orally fed proteins from the gut to the blood serum in the suckling rat. Biol Neonate 41:85-93

12. Carpenter $G 1980$ Epidermal growth factor is a major growth-promoting agent in human milk. Science 210:198-199

13. Udall JN, Colony P, Fritze L, Pang K, Trier JS, Walker WA 1981 Developmen of gastrointestinal mucosal barrier. II. The effect of natural versus artificial feeding on intestinal permeability to macromolecules. Pediatr Res 15:245249

14. Udall JN, Walker WA 1982 The physiologic and pathologic basis for the transport of macromolecules across the intestinal tract. J Pediatr Gastroenterol Nutr 1:295-301

\title{
Pulmonary Toxicity of Monocrotaline Differs at Critical Periods of Lung Development
}

\author{
LIVIA TODD, MICHELLE MULLEN, PETER M. OLLEY, AND MARLENE RABINOVITCH \\ Departments of Cardiology and Pathology, Research Institute. The Hospital for Sick Children and Departments \\ of Paediatrics and Pathology, University of Toronto, Toronto, Canada
}

\begin{abstract}
We injected 3-day-old (neonatal), 8-day-old (infant), and 8-wk-old (adult) Sprague-Dawley rats with monocrotaline to examine the effect of a toxic agent at various stages of lung development. Two and four weeks after injection the rats were killed and the heart and lungs removed: the right and left ventricles were separated and weighed, the pulmonary artery was injected with bariumgelatin, and the lung was fixed in the inflated state. Morphometric techniques were applied to assess lung volume, alveolar size and number, and arterial size, muscularity, and concentration relative to alveolar. Rats injected with monocrotaline in the neonatal period did not survive to 3 wk. After 2 wk, there was no significant right ventricular hypertrophy and pulmonary vascular changes were no worse than in the other rat groups injected with monocrotaline, but alveolar development was severely impaired; less than one-third the normal number was present. Rats injected with monocrotaline in infancy had normal alveolar development. After 2 -wk, the arterial changes, i.e. extension of muscle into peripheral arteries, medial hypertrophy of muscular arteries, and decreased arterial concentration relative to alveolar were similar to those observed in adult rats. After $4 \mathrm{wk}$, there was a decrease in medial hypertro-
\end{abstract}

Received September 28, 1984; accepted March 11, 1985

Requests for reprints Dr. Marlene Rabinovitch, Department of Cardiology, The Hospital for Sick Children, 555 University Avenue, Toronto, Ontario, Canada M5G 1 X8.

Supported by the Department of Anatomy and the Independent Studies Program at Trinity College, University of Toronto and by the Ontario Heart Foundation (Grant 0HF4-14).M.R is a Research Associate of the Ontario Heart Foundation. phy associated with growth in artery size and only a lack of regression of right ventricular weight. In adult rats, after 4 wk medial hypertrophy became progressively more severe, the arterial concentration relative to alveolar decreased further, and right ventricular hypertrophy developed. Thus, exposure to a toxic agent in the newborn period may have a critical effect on alveolar development, whereas arterial changes induced by a toxic agent during infancy may regress if there is potential for growth of the pulmonary vascular bed.

A toxic insult may be expected to affect lung development. The newborn rat exposed chronically to hyperoxia will have impaired alveolar and arterial growth $(1,2)$ and the young rat exposed chronically to hypoxia will have more severe pulmonary vascular changes than the adult (3). Monocrotaline is a cytotoxic compound derived from the seeds of Crotalaria spectabilis (4). When administered orally or by injection in adult rats, the pyrrolizidine alkaloid metabolite induces endothelial injury and causes progressive pulmonary vascular changes and right ventricular hypertrophy (5-9). The effects it might have in the developing lung have not been previously studied and could contribute to understanding the response to inflammation and mechanisms of pulmonary hypertension in the newborn and young infant. Meyrick et al. (10) observed that the developing lung passes through two critical periods of growth, one related to alveolar multiplication (3-8 days of age) the other to arterial 

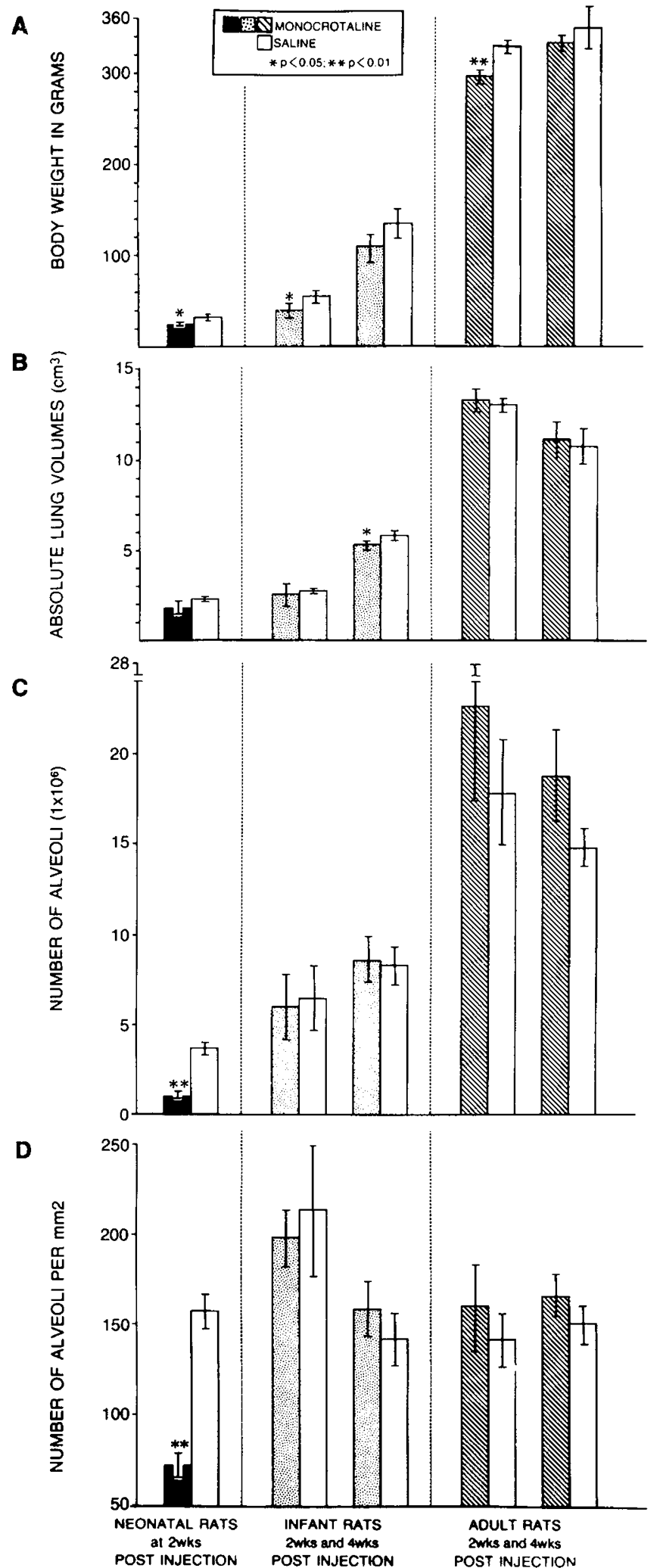

Fig. 1. $A$, growth. Body weight in grams increases with age and with duration of the experiment in both saline control (open bar) and monocrotaline injected (closed and hatched bar) rats, although there is always less weight gain in the latter. $B$, total lung volumes. Lung volume increases with age but in adult rats there is a decrease with increasing duration of the experiment. $C$, total number of alveoli. The number of alveoli increases with age but decreases with duration of the experiment in adult rats. Monocrotaline reduces alveolar number, only in the neonatal group. $D$, alveolar concentration. Alveolar concentration (no./ proliferation (8-11 days). We compared the nature and severity of monocrotaline-induced pulmonary toxicity after a single subcutaneous injection in 3-day (neonatal), 8-day (infant), and 8wk-old (adult) rats.

\section{MATERIALS AND METHODS}

Sixteen adult male and four litters of Sprague-Dawley rats (male and female) were used. Two of the four litters, chosen at random, were designated neonates and injected at 3 days of age, alternate litermates receiving monocrotaline or saline. The other two litters were designated infants and injected in a similar fashion at 8 days of age. Adult rats were all injected at 8 wk of age. All injections were administered subcutaneously in the hindflank; the dose of monocrotaline was $60 \mathrm{mg} / \mathrm{kg}$; the physiologic saline injection was of an equal volume. To prepare monocrotaline, $200 \mathrm{mg}$ of the crystalline compound were dissolved in $0.6 \mathrm{ml}$ of normal $\mathrm{HCl} ; 5 \mathrm{ml}$ of distilled water was added and the $\mathrm{pH}$ adjusted to 7.0 with $0.5 \mathrm{~N} \mathrm{NaOH}$ and diluted to a final volume of $10 \mathrm{ml}(5)$.

At 2 and 4 wk postinjection equal numbers of experimental rats along with their age-matched controls were weighed and then sacrificed by an intraperitoneally administered overdose of sodium pentobarbital $(300 \mathrm{mg} / \mathrm{kg})$. The heart and lungs were removed en bloc. The pulmonary artery and trachea were cannulated, and then the heart and lungs were deep frozen at $-22^{\circ} \mathrm{C}$ to be injected in batches at a later date (usually within 2 wk). At that time the lungs were thawed, incubated at $37^{\circ} \mathrm{C}$ for $1 \mathrm{~h}$ and the pulmonary artery injected with a hot $\left(60^{\circ} \mathrm{C}\right)$ radiopaque barium-gelatin mixture $(6,11)$ at $100 \mathrm{~mm} \mathrm{Hg}$ pressure for $5 \mathrm{~min}$. The lungs were then distended by intratracheal infusion of $10 \%$ formaldehyde (at room temperature) at $36 \mathrm{~cm}$ water pressure and perfused continuously for 3 days. The right ventricle and left ventricle with septum were then dissected and weighed separately (12). The ventricular weights were expressed as the ratio right ventricle/(left ventricle plus septum) and were related to body weight (right ventricle per body weight, left ventricle plus septum per body weight). The lung volume for each animal was measured by water displacement. Arteriograms were taken at $35 \mathrm{kev}$ for 0.4 or at $45 \mathrm{kev}$ for $0.6 \mathrm{~s}$, depending on the size of the lung. The arteriograms were magnified 10 times. The density of background vessels was assessed qualitatively but the length of the axial artery was measured as well as its lumen diameter at three points: at the hilum of the lung, at the midlung (50\% of the distance from the hilum to where the vessel appeared to end), and at the periphery ( $90 \%$ of the distance).

From each animal, a single block $\left(1 \times 1 \times 0.2 \mathrm{~cm}^{3}\right)$ was dissected from the middle region of the fixed left lung and prepared for histologic analysis. From each block a 5- $\mu \mathrm{m}$ section was cut and stained by the elastic Van Gieson method. Using the barium injection technique there was filling of preacinar and intraacinar arteries down to a diameter of $15 \mu \mathrm{m}$ as has been previously observed (11). Only occasionally did an artery fail to fill with barium (approximately $1-2$ in 50 or $2-4 \%$ ). In each tissue section, the structure of at least 50 consecutive barium filled arteries was analyzed, usually at $400 \times$ magnification. For each artery, the structure of the accompanying airway was identified as preacinar, terminal bronchiolus, respiratory bronchiolus, alveolar duct, or alveolar wall. The external diameter of each barium-filled artery was measured, and the structure of the vessel was noted as muscular, partially muscular, or nonmuscular. The percentage of muscular and partially muscular arteries at each airway level was calculated, and for each of these arteries, the medial thickness was related to the external diameter as a per-

$\mathrm{mm}^{2}$ ) is influenced by age (but only in the infant group where it was increased) and by monocrotaline in the neonatal group where it is reduced. ${ }^{*} p<0.05,{ }^{* *} 0.001$, Student's $t$ test, differences were also significant by 2 - and 3-way analyses of variance (see text). 

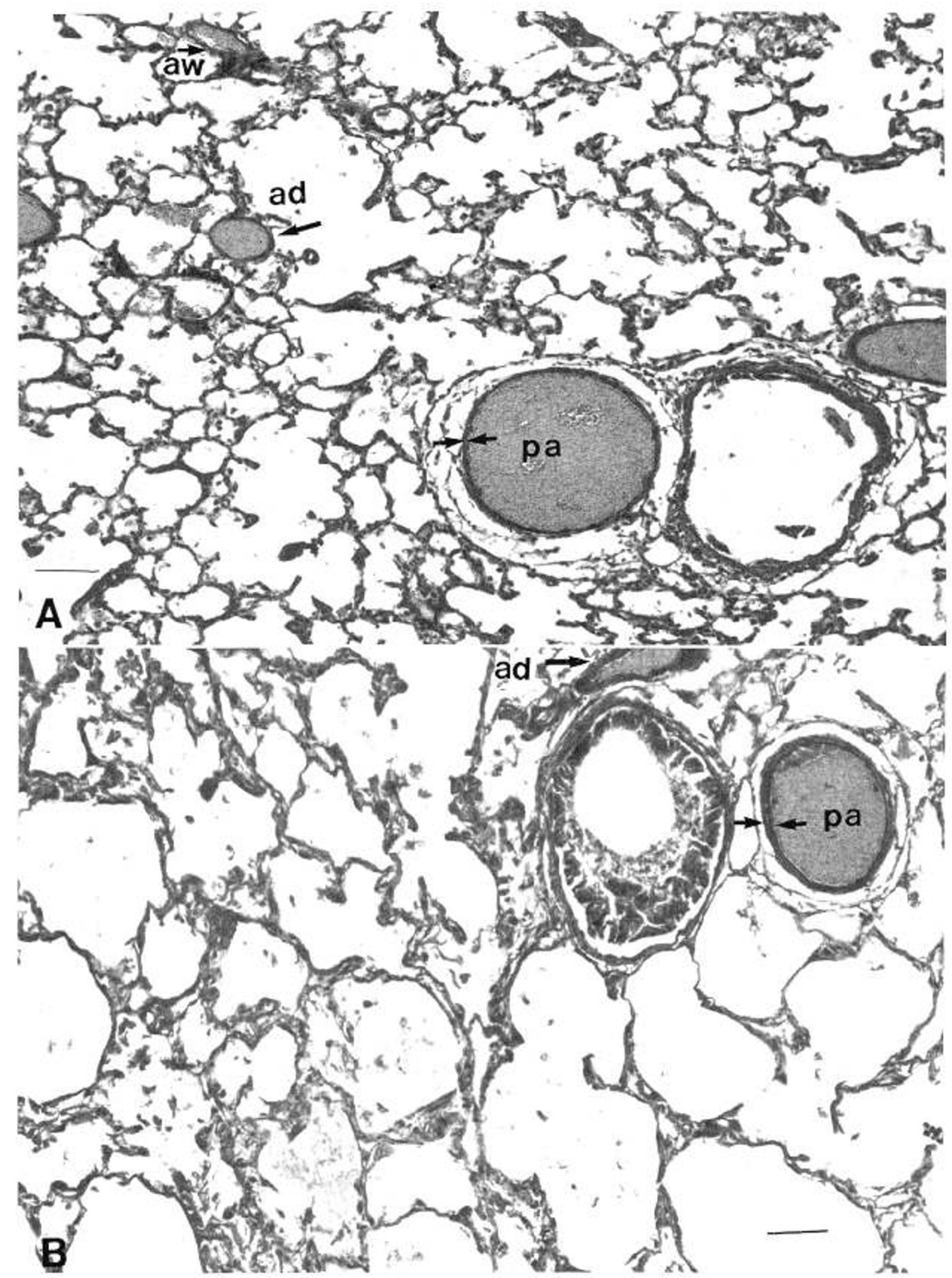

Fig. 2. A, photomicrographs of neonatal lung. Photomicrograph of a lung tissue section in a control neonatal rat 2 wk after saline injection. Observe muscular preacinar ( $\mathrm{pa}$ ) artery of normal wall thickness (arrows) and numerous nonmuscular alveolar duct and wall ( $a d, a w)$ arteries. Note normal proportion of alveoli and arteries in the field. $B$, photomicrograph of a lung tissue section in a neonatal rat 2 wk after monocrotaline injection. Observe thick walled preacinar ( $p a)$ artery (arrows) and abnormally muscular alveolar duct $(a d)$ artery. Note few alveoli $/ \mathrm{mm}^{2}$ and few arteries. ( $B a r=50 \mu \mathrm{m}$, elastic Van Gieson stain). 
Table 1. Ratios of right and left ventricular wt also related to body wt (mean $\pm S E$ )

\begin{tabular}{|c|c|c|c|c|c|c|c|c|}
\hline \multirow[b]{2}{*}{ Group } & \multirow{2}{*}{$\begin{array}{l}\text { Time after injection } \\
\text { of monocrotaline or } \\
\text { saline (wk) }\end{array}$} & \multirow{2}{*}{$\begin{array}{c}n \\
\text { studied }\end{array}$} & \multicolumn{2}{|c|}{$\mathrm{RV} /(\mathrm{LV}+\mathrm{S})$} & \multicolumn{2}{|c|}{$\begin{array}{l}\text { RV/body wt } \\
(\mathrm{g} / \mathrm{kg})\end{array}$} & \multicolumn{2}{|c|}{$\begin{array}{l}\text { LV/body wt } \\
\text { (g/kg) }\end{array}$} \\
\hline & & & Saline & Monocrotaline & Saline & Monocrotaline & Saline & Monocrotaline \\
\hline Neonatal & 2 & 6 & $0.257 \pm 0.012$ & $0.308 \pm 0.082$ & $0.094 \pm 0.20$ & $1.26 \pm 0.22$ & $3.56 \pm 0.61$ & $4.30 \pm 0.43$ \\
\hline \multirow[t]{2}{*}{ Infant } & 2 & 8 & $0.330 \pm 0.025$ & $0.435 \pm 0.082$ & $0.97 \pm 0.11$ & $1.45 \pm 0.25$ & $2.91 \pm 0.14$ & $3.35 \pm 0.25$ \\
\hline & 4 & 8 & $0.292 \pm 0.030$ & $0.434 \pm 0.056^{*}$ & $0.74 \pm 0.07$ & $1.10 \pm 0.08^{* *}$ & $2.55 \pm 0.06$ & $2.60 \pm 0.15$ \\
\hline \multirow[t]{2}{*}{ Adult } & 2 & 8 & $0.295 \pm 0.032$ & $0.279 \pm 0.022$ & $0.62 \pm 0.07 \dagger$ & $0.60 \pm 0.07$ & $2.10 \pm 0.04 \dagger \dagger$ & $2.10 \pm 0.12$ \\
\hline & 4 & 8 & $0.270 \pm 0.014$ & $0.453 \pm 0.028^{* *}$ & $0.60 \pm 0.03$ & $1.0 \pm 0.08^{* *}$ & $2.20 \pm 0.07$ & $2.20 \pm 0.08$ \\
\hline
\end{tabular}

Abbreviations: $n$, number of rats; $\mathrm{RV}$, right ventricle; $(\mathrm{LV}+\mathrm{S})$, left ventricle and septum; $\mathrm{LV}$, left ventricle.

${ }^{*} p<0.05 ;{ }^{* *} p<0.01$ represent $t$ test comparisons of monocrotaline versus saline; these features were also significant by analysis of variance (see text); $\dagger p<0.01 ; \dagger \dagger p<0.001$ represent age-related differences by analysis of variance; $p$ values related to 2- and 3-way analyses of variance found in text.

centage wall thickness (according to the formula)

$$
\frac{2 \times \text { medial thickness }}{\text { external diameter }} \times 100=\% \text { wall thickness }
$$

In 20 consecutive fields (each $0.2 \mathrm{~mm}^{2}$ ) all the arteries including the occasional nonbarium filled vessels and all the alveoli were counted and the number of each per $/ \mathrm{mm}^{2}$ calculated taking into acount the shrinkage factor of the processed tissue. Arterial concentration relative to alveloar was assessed as the number of arteries per 100 alveoli. Alveolar concentration no. alveoli $/ \mathrm{mm}^{2} /$ shrinkage factor was used to calculate total number of alveoli according to the following formula $(14,15)$

$$
\frac{\left[\frac{\text { no. alveoli } / \mathrm{mm}^{2}}{\text { shrinkage factor }}\right]^{3 / 2}}{1.55 \times \sqrt{\mathrm{p}}} \times \text { lung vol }\left(\mathrm{mm}^{3}\right)=\text { total no. alveoli }
$$

1.55 is the spherical constant for an alveolus (13) and $\sqrt{ } \mathrm{p}$ is the volume proportion of alveoli derived by point counting the microscopic section $(14,15)$.

Analysis of data. Complete data were available for three rats in each of the neonatal groups 2 wk postinjection and four rats in each of the infant and adult rat groups at both 2 and 4 wk postinjection. All arteriograms and microscopic sections were examined without knowledge of the experimental group to which the animal belonged. Differences between monocrotaline-treated and age-matched controls were compared by Student's $t$ test and by 2- and 3-way analysis of variance: $p$ values given in the text are related to analysis of variance testing.

\section{RESULTS}

Growth. In the neonatal rat group $20 \%$ of monocrotaline rats died before the first assessment at $2 \mathrm{wk}$; none of the rats survived to the second assessment at $4 \mathrm{wk}$ and almost all died shortly after the 2 nd wk. While postmortem examination was not feasible, the abnormalities in pulmonary development observed in neonatal rats 2 wk after monocrotaline injection suggest the likely cause of death, and these will be discussed. All rats in the other groups survived.

The latter rats (monocrotaline and saline) continued to grow in size (body weight) after injection. However, monocrotaline impaired growth, in that the body weights of experimental animals were consistently reduced relative to controls $(p<0.001)$ (Fig. $1 A$ ). In the infant and adult rat groups, the difference in weight between monocrotaline and saline injected rats appeared greater $2 \mathrm{wk}$ after injection than $4 \mathrm{wk}$ later. In the infant rat group this feature correlated with regression of structural abnormalities. In the adult group there was considerable ascites in the experimental animals $4 \mathrm{wk}$ after injection accounting for the lesser difference and suggesting right heart failure or hepatic toxicity.

Lung growth. Lung volume was increased with age in both the monocrotaline and saline rats $(p<0.001)$. In the infant group lung volume increased with duration after injection but in the adult group it decreased $(p<0.001)$ (Fig. $1 B)$.

The total number of alveoli increased almost 10 -fold with age. It increased with duration after injection in the infant group but not in the adult (Fig. $1 C$ ). In the latter rats, alveolar number was decreased in proportion to the decrease in lung volume $(p<$ $0.05)$. Only in the neonatal rat group did monocrotaline affect alveolar number, decreasing it to a third the normal value $(p<$ 0.01 ). This was apparent on a 2-way analysis of variance when the logarithm of the alveolar number was assessed, dampening the overwhelming effect of age.

Monocrotaline injection caused a decrease in alveolar concentration in the neonatal group (Fig. 1D). This coupled with the decrease in alveolar number in the neonatal group accounts for the normal lung volume observed (Fig. $2 A$ and $B$ ).

Right ventricular hypertrophy. In all control rats, right ventricular weights (relative to that of left ventricle and septum) were similar. Both right and left ventricular weights relative to body weight decreased with age $(p<0.001$, and $<0.01$ respectively, Table 1). Monocrotaline induced right ventricular hypertrophy but this was significant only $4 \mathrm{wk}$ after injection $(p<0.01$, Table 1). In the infant rat group the right ventricular hypertrophy appeared to result from lack of regression of right ventricular weight, whereas in the adult group there was a progressive increase.

Pulmonary vascular growth and development. In all rats arterial size, as judged by the lumen diameter of the axial arteries on the arteriogram, increased with age. In the infant rat group this feature was apparent with increasing duration after injection as the animals were still growing, but not in the adult group since the rats (and their vessels) were fully developed. Monocrotaline did not significantly influence arterial size in any rat group (Fig. $3 A)$.

On the arteriograms, the density of peripheral arteries is apparent as a background haze (Fig. $4 A$ ). The haze represents vessels that ordinarily fill with barium but are too small to be resolved as individual lines. Background haze was similar in all control rats but was appreciably reduced in monocrotaline groups both 2 and 4 wk after injection (Fig. $4 B$ ).

On microscopic examination of the lung specimens, arterial concentration relative to alveolar (Fig. $3 B$ ) and arterial muscularity judged by extension of muscle into normally nonmuscular peripheral arteries (Fig. $3 C$ ) and medial hypertrophy of muscular arteries (Fig. $3 D$ ) was similar in control animals of all age groups over the duration of the experiment (Fig. 2A). Monocrotaline reduced the concentration of arteries relative to alveoli similarly in rats of all ages $(p<0.01)$ (Figs $2 B$ and $3 B$ ). In the infant group there was a trend toward a return to normal arterial concentration with increasing duration after injection, whereas in the adult group the trend was toward continued reduction (Fig. $3 B$ ). Monocrotaline caused extension of muscle into peripheral arteries similarly in all age groups $(p<0.001)$ (Figs. $2 B$ and $3 C$ ). Duration after injection had no effect on the severity of this structural feature. Monocrotaline also induced medial hypertrophy of muscular arteries in all groups $(p<0.001)$ (Fig. 


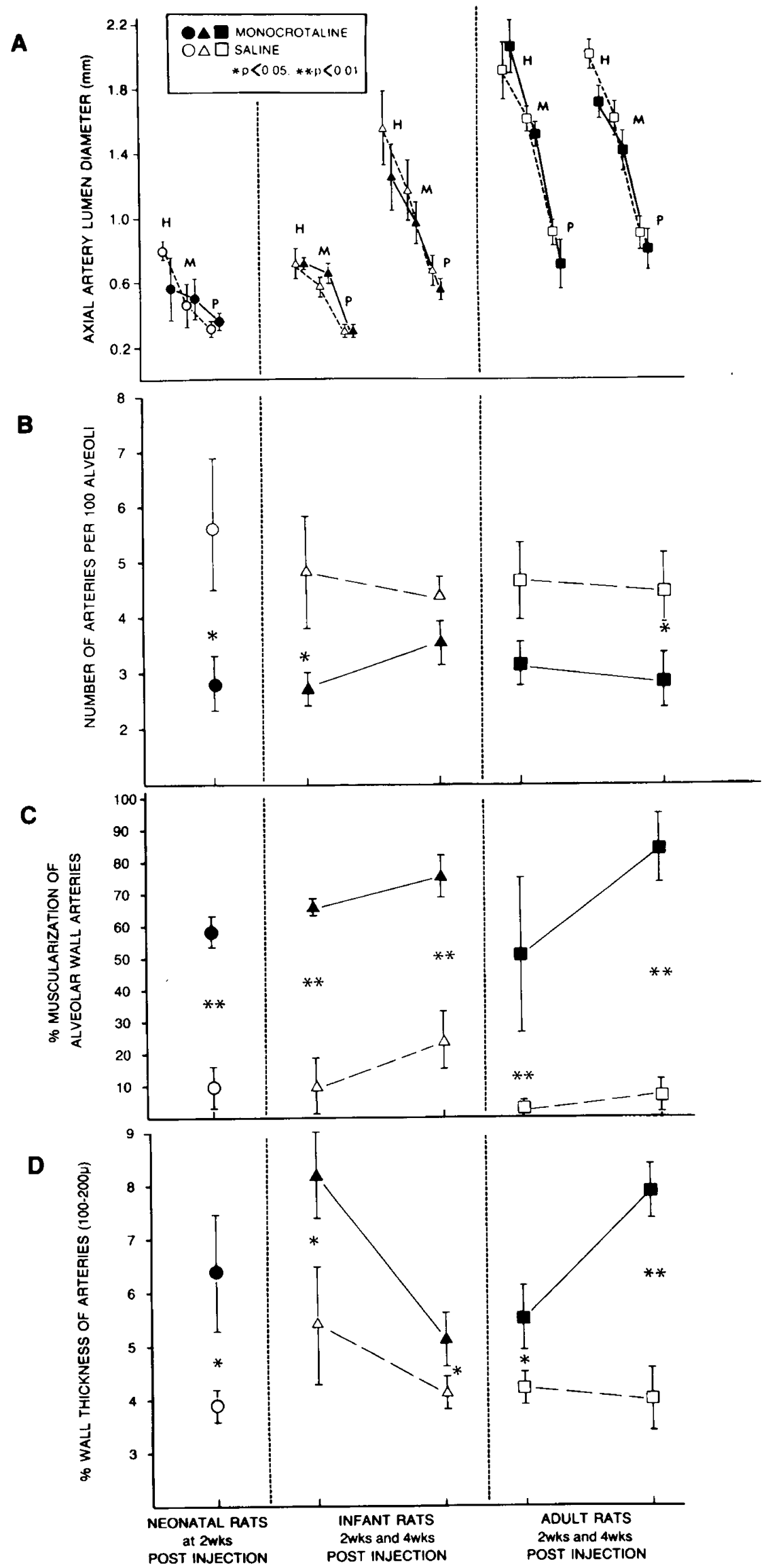

Fig. 3. $A$, arterial size. Lumen diameter of the axial artery measured on the arteriogram at hilum $(H)$, midlung $(M, 50 \%$ from hilum), and periphery $(P, 90 \%$ from periphery). The lower limit of artery diameter measured is $200 \mu \mathrm{m}(0.2 \mathrm{~mm})$. Monocrotaline does not significantly affect artery size. Artery diameter doubles with increasing duration of the experiment in the infant group but does not change in the adult group. $B$, arterial concentration relative to alveoli. A decreased concentration of arteries relative to alveoli is a feature of all monocrotaline-treated rats. In the infant group there is a trend toward a return to normal values $4 \mathrm{wk}$ after the injection. $C$, extension of muscle. Extension of muscle into peripheral arteries, judged by an increased percentage of arteries at alveolar wall level fully and partially muscularized is apparent in all monocrotaline injected rats. $D$, medial hypertrophy. An increase in wall thickness of normally muscularized arteries is evident in all monocrotaline injected rats. In the infant rats medial hypertrophy regresses with increasing duration after the injection whereas in the adult rats it increases. 

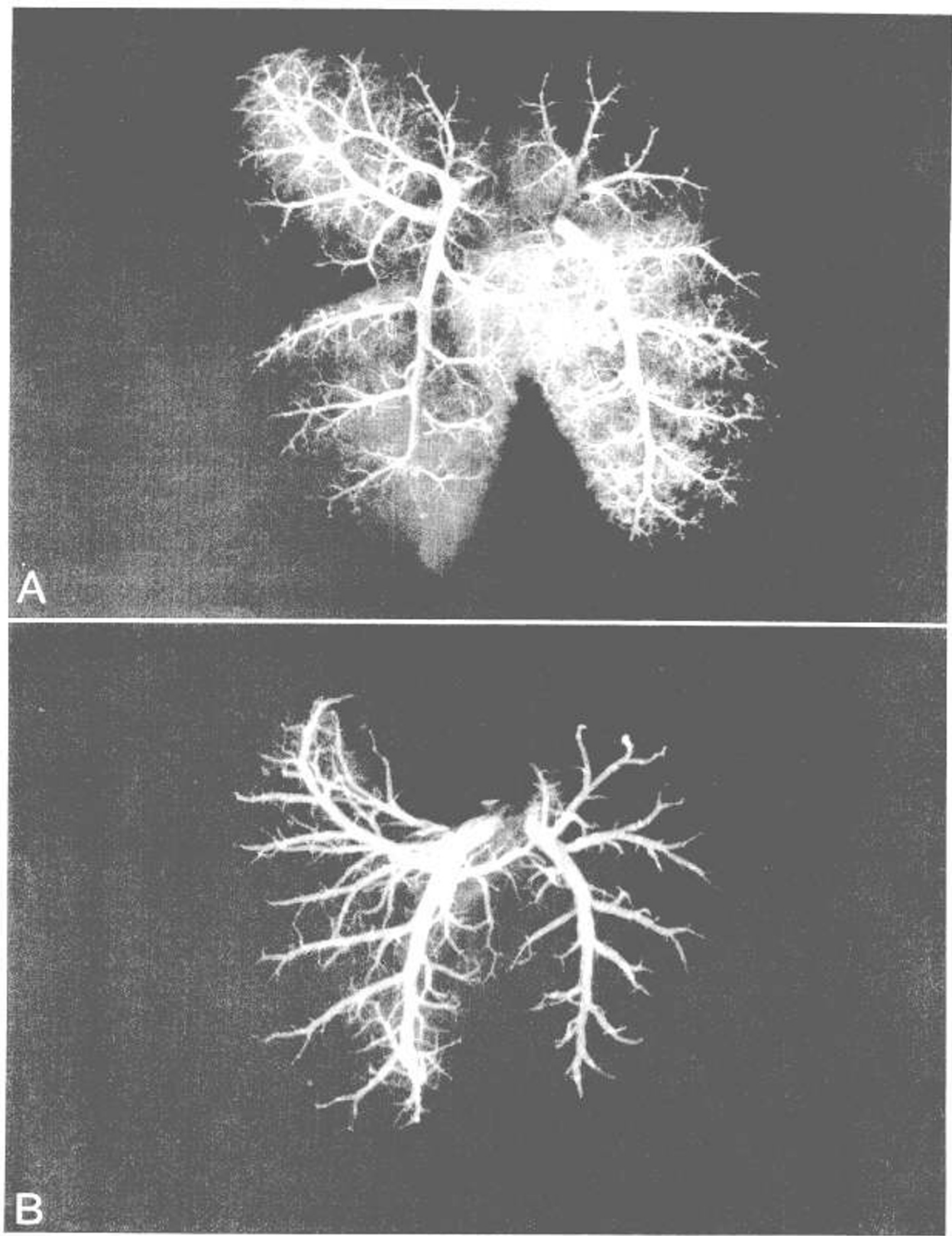

Fig. 4. $A$ and $B$, arteriograms of neonatal lungs. In $A$, the arteriogram of a control neonatal lung 2 wk after saline shows a dense haze of background vessels filled with barium compared with the neonatal lung 2 wk after monocrotaline injection in $B$.

$2 B$ ). With increasing duration after injection, medial hypertrophy appeared to regress in the infant group but progressed in the adult animals $(p<0.05)$.

\section{DISCUSSION}

Effect of monocrotaline in neonatal rats. Ross (16) analyzed some of the secondary cytologic effects of alkylating agents such as monocrotaline (4). Of particular interest is the cytostatic effect in which mitosis is delayed or prevented. This finding is clearly applicable in our studies where a probable cytostatic effect of monocrotaline is to prevent alveolar growth. The neonatal rats injected with monocrotaline probably do not survive because they are affected during the critical period for alveolar development (3-8 days) (17). These rats have a severely reduced number 
of alveoli and in addition, the normal subsequent burst of arterial proliferation does not occur (17). Moreover, since a toxic effect of monocrotaline is to cause endothelial injury with swelling and closing off of vessels $(10)$, there is also a reduced concentration of arteries relative to alveoli. This feature is no worse than in rats of other age groups, but owing to the reduced number of alveoli, absolute arterial number is more severely decreased. The cause of death in the neonatal rats thus is likely due to inadequate gas exchange secondary to a severe reduction in the number of alveoli and arteries. Although we had no arterial blood gas values, the alveolar number was one-third normal $2 \mathrm{wk}$ after injection, and there is evidence from clinical studies that this degree of reduction (18) may be incompatible with life (19). We could not rule out the possibility that death was related to other features of monocrotaline toxicity, but at $2 \mathrm{wk}$ after injection, at least on gross inspection, no other organs, e.g. liver, seem to have been affected.

Effect of monocrotaline in infant rats. It appears that once the early burst of alveolar multiplication is initiated, monocrotaline will cause no further impairment of alveolar development. It is in the infant group that the pulmonary artery increases in size over the duration of the experiment, a feature unaffected by monocrotaline. This suggests that the stimulus for arterial growth may be independent of both the endothelial injury and the increase in medial smooth muscle which occur after monocrotaline injection in both small and large vessels (9). Moreover, whatever stimulates arterial growth seems to inhibit further medial hypertrophy. As the vessel grows, the wall thins. In adult rats there is no potential for arterial growth so medial hypertrophy progresses.

In the infant rat group there is a trend toward an increase in arterial concentration with increasing duration after monocrotaline injection, suggesting that proliferation of new arteries may be occurring. Yet there is no evidence of regression of extension of muscle. We can only speculate that this is because increase in peripheral vessels produces an increase in flow which maintains extension (20).

Our previous clinical studies support the finding that growth of the pulmonary vascular bed is associated with regression of structural changes. In children with congenital heart defects and left to right shunts, early surgical correction is associated with regression of the vascular changes resulting from increased pulmonary artery pressure and flow (21).

Effect of monocrotaline in adult rats. The adult rats (both experimental and control) show a decrease in lung volume and in total alveolar number with increasing duration of the experiment. We can only speculate that with aging the lung may become stiffer and not able to expand as fully under high pressure. The decrease in alveolar number is difficult to explain unless there is some coalescence of alveoli with aging. Vascular abnormalities are similar to those previously reported (17).

Future applications. We have established a model in which alveolar multiplication can be arrested in the neonatal period. Future studies aimed at identifying the cellular mechanism responsible for this abnormality may suggest ways to induce alveolar multiplication in clinical disease associated with hypoplastic and dysplastic lungs. We have shown that a toxic insult affects the lung differently at critical periods of development. When it occurs early it may be fatal as it may affect alveolar growth which precedes and perhaps determines subsequent arterial proliferation. When it occurs later, it may be overcome because of the potential for growth of the pulmonary vascular bed. This may explain why the only reported cases of spontaneous regression of idiopathic pulmonary hypertension have occurred in childhood $(22,23)$.

Acknowledgments. The authors gratefully acknowledge the help and advice of Dr. Margaret M. Wood, biostatistician, The Hospital for Sick Children, Professor Ian Taylor, Department of Anatomy, and Professor G. A. B. Watson Department of Religious Studies, University of Toronto. We thank Ms. Pamela Longley and Ms. Toni Smith for their secretarial assistance as well as Ms. Eva Struthers and Mr. Ray Caesar for the illustrations.

\section{REFERENCES}

1. Frank L Bucher JR, Roberts RJ 1978 Oxygen toxicity in neonatal and adult animals of various species. J Appl Physiol 45:699-704

2. Roberts RJ, Weesner KM. Bucher JR 1983 Oxygen-induced alterations in lung vascular development in the newborn rat. Pediatr Res 17:368-375

3. Rabinovitch M. Gamble WJ, Miettinen OS, Reid LM 1981 Age and sex influence on pulmonary hypertension of chronic hypoxia and on recovery. Am J Physiol 240:H62-H72

4. Hayashi $Y 1966$ Excretion and alteration of monocrotaline in rats after a subcutaneous injection. Fed Proc 25:688(abstr)

5. Hayashi Y, Lalich JJ 1967 Renal and pulmonary alterations induced in rats by a single injection of monocrotaline. Proc Soc Exp Biol Med 124:392-396

6. Hislop A. Reid L 1974 Arterial changes in crotalaria spectabilis-induced pulmonary hypertension in rats. Br J Exp Pathol 55:153-163

7. Huxtable R. Paplanus S, Laugharn BS 1977 The prevention of monocrotaline induced right ventricular hypertrophy. Chest 71 (Suppl):308-310

8. Kay JM. Keane PM. Suyama KL. Gauthier D 1982 Angiotensin converting enzyme activity and evolution of pulmonary vascular disease in rats with monocrotaline pulmonary hypertension. Thorax 37:88-96

9. Meyrick B. Reid L 1979 Development of pulmonary arterial changes in rats fed Crotalaria spectabilis. Am J Pathol 94:37-50

10. Meyrick B, Gamble W. Reid L 1980 Development of crotalaria pulmonary hypertension: hemodynamic and structural study. Am J Physiol 239:H692H702

11. Hislop A. Reid L 1976 New findings in pulmonary arteries of rats with hypoxiainduced pulmonary hypertension. Br J Exp Pathol 57:542-554

12. Fulton RM. Hutchinson EC, Jones AM 1952 Ventricular weight in cardiac hypertrophy. Br Heart J 14:413-420

13. Weibel ER. Gomez DM 1962 A principle for counting tissue structures on random sections. J Appl Physiol 17:343-348

14. Dunnill MS 1962 Quantitative methods in the study of pulmonary pathology. Thorax 17:320-328

15. Dunnill MS 1962 Postnatal growth of the lung. Thorax 17:329-333

16. Ross WC 1962 Biological alkylating agents. Buttersworth, London

17. Meyrick B. Reid L 1982 Pulmonary arterial and alveolar development in normal postnatal rat lung. Am Rev Respir Dis 125:468-473

18. Hislop A, Fairweather DVI 1984 Alveolar number and size in the human fetal and neonatal lung. Am Rev Respir Dis 129:A208

9. Bohn D. Rabinovitch M. Tamura M. Bryan AC, Barker GA 1984 The relationship between $\mathrm{PaCO}_{2}$ and ventilatory parameters in predicting mortality in congenital diaphragmatic hernia. Am Rev Respir Dis 129:A212(abstr)

20. Rabinovitch M. Konstam MA, Gamble WJ, Papanicolaou N, Aronovitz MJ Treves S. Reid LM 1983 Changes in pulmonary blood flow affect vascular response to chronic hypoxia in rats. Circ Res 52:432-441

21. Rabinovitch M, Keane JF, Norwood WI Castaneda AR, Reid LM 1984 Vascular structure in lung tissue obtained at biopsy correlated with pulmonary hemodynamic findings after repair of congenital heart defects. Circulation 69:655-667

22. Bourdillon PDV Oakley CM 1976 Regression of primary pulmonary hypertension. Br Heart J 38:264-270

23. Fujii A, Rabinovitch M, Matthews EC 1981 A case of spontaneous resolution of idiopathic pulmonary hypertension. Br Heart J 45:574-577 